\title{
RBEP
}

\section{O primeiro decênio da Capes: uma campanha extraordinária (1951-1960)}

Fernando Gouvêa

\section{Resumo}

Objetiva analisar o primeiro decênio de existência da Campanha de Aperfeiçoamento de Pessoal de Nível Superior (Capes), que abarca o período de 1951 a 1960, situando a instituição no âmbito do aparelho estatal federal num contexto histórico marcado pelo modelo nacionaldesenvolvimentista. O caminho para o alcance deste objetivo tem como elementos essenciais a utilização de relatórios, correspondências, mensagens presidenciais e documentos legais articulados sob o signo da utilização de estratégias e táticas por indivíduos-coletivos, que edificaram uma rede institucional que levou a Capes a um papel central na elaboração de políticas públicas educacionais no seio do Ministério da Educação. Tal centralidade teve como resultado a tentativa de construção de um sistema nacional de pós-graduação que se constitui num legado a ser examinado no tempo presente.

Palavras-chave: Capes; Inep; história da educação brasileira; 1951-1960. 


\section{Abstract}

The first decade of capes: an extraordinary campaign (19511960)

This article analyzes the first decade of existence of the Campaign for the Improvement of Higher Level Personnel (Capes), covering the period of 1951 to 1960. It places the institution within the federal state apparatus in a historical context marked by the national-developmentalist model. To achieve this goal, reports, correspondence, legal documents and presidential messages were jointly analyzed, articulated under the sign of the use of strategies and tactics by collective-individuals. These actors built an institutional network that led Capes to a central role in the education policy-making process within the Ministry of Education. This centrality has resulted in the attempt to build a national system of graduate school whose legacy has to be examined in the present.

Keywords: Capes; Inep; history of brazilian education; 1951-1960.

\section{Introdução}

A análise de documentos sempre significa um desafio ao pesquisador. A questão do período em que o documento foi escrito, a autoria e as contribuições relevantes a serem extraídas tornam tal estudo um momento significativo e que pode propiciar um outro olhar sobre temas e construções tacitamente aceitas.

Um olhar que possibilite, perante o documento, a apreensão das vozes e dos silêncios, das estratégias lançadas e das táticas acionadas por indivíduos-coletivos, do processo interno anterior à externalização de um projeto, enfim, de tudo aquilo que está no antes e no para além dos marcos regulatórios tradicionais na configuração de uma rede institucional (Certeau, 1994; Elias, 1994).

Desta forma, o estudo sobre o primeiro decênio da Campanha de Aperfeiçoamento de Pessoal de Nível Superior (Capes) - criada pelo Decreto n 29.741, de 1951 - exigiu a utilização de relatórios, correspondências, mensagens presidenciais e obras voltadas para a história da instituição. Esses instrumentos se mostraram imprescindíveis para o desvelamento do período inicial da Campanha, das políticas públicas educacionais e da ação estatal, no âmbito geral, que orientaram essa instituição nos anos 1950-1960, acentuadamente marcados pela ideologia nacional-desenvolvimentista, os quais considero o período de formação institucional e de solidificação das ideiaschave sobre o papel, a estrutura e a dinâmica de atuação da Capes. 


\section{A correspondência "fundadora": "sugestões para um plano de auxílio ao ensino superior do País"}

O documento "Sugestões para um plano de auxílio ao ensino superior do País", datado de 1950, chama a atenção por ser um plano de ação sugerido por Anísio Teixeira - à época, secretário estadual de Educação e Saúde da Bahia - ao então ministro da Educação Clemente Mariani. A leitura desse documento indicou a existência de um conjunto de ideias sobre o ensino superior e a pós-graduação no Brasil. Nele, Teixeira teceu críticas ao processo de seleção de professores e alunos para o ensino superior, ao afirmar que "para melhorar a qualidade do ensino, o auxílio pode consistir em disposições que concorram para uma seleção mais alta dos alunos [...], em recursos para melhorar as instalações e equipamentos, e, sobretudo e acima de tudo, em melhores professores".

Teixeira apontou, ainda, a urgência de um levantamento das reais necessidades de quadros superiores para o País, e "como não é possível, com o recurso tão somente ao elemento nacional", aventou a possibilidade da contratação de professores estrangeiros e sugeriu também critérios para a seleção de alunos para bolsas de estudo no exterior. Tais aspectos levantados por Teixeira, ainda em 1950, foram os pilares da implementação e do processo de formação da Capes, na medida em que expressaram ideias basilares quanto ao papel do ensino superior e da pós-graduação na transformação da educação brasileira (Gouvêa, Mendonça, 2006).

As proposições destacadas do corpo das "sugestões" foram encontradas em diversos documentos da fase inicial da Capes e confirmam a tese da permanência, do aprofundamento e do alargamento da compreensão de Teixeira e de seus colaboradores sobre a política de atuação dessa instituição. A cuidadosa análise de tais documentos também evidenciou a preocupação com a descentralização e com a organização de um sistema nacional de educação.

No documento "Fase preliminar da Capes - atitudes emergenciais", datado de 1951, Anísio Teixeira considerou que a criação da Capes possibilitava "o reconhecimento dessa necessidade de se planejar o preparo e a distribuição adequada de pessoal formado e especializado" e explicitou o estabelecimento dos critérios para a realização de um levantamento das necessidades de pessoal de nível superior para o País, "[...] tendo em vista: desenvolvimento e expansões atuais e desenvolvimento e expansões potenciais". Teixeira ainda propugnava a utilização das seguintes fontes: mensagens dos últimos anos dos governadores de Estado, publicações do Instituto Brasileiro de Geografia e Estatística (IBGE), planos estaduais de desenvolvimento, publicações estatísticas dos Estados, planos e publicações federais e publicações da Fundação Getúlio Vargas; uma vasta documentação a ser consultada, confirmando a importância desse levantamento e o desafio para a Capes de realizar algo de tais proporções. 
O documento apresentou, também, algumas inferências preliminares sobre o referido levantamento e expressou a posição de urgência no tocante às providências imediatas a serem tomadas, pois

[...] parece, assim, fora de qualquer dúvida que a educação, formação e especialização do homem brasileiro é um problema de ordem econômica e de altíssima prioridade, que deve ser encarado entre os problemas de base do desenvolvimento brasileiro, cuja rentabilidade indireta é a mesma dos demais problemas de base como transportes e indústrias básicas [...]. (Teixeira, 1951).

A urgência é tão expressiva que o relatório trouxe uma sugestão capital quanto ao processo de inserção da Capes no âmbito da burocracia estatal:

[...] a incorporação da Campanha ao Instituto Nacional de Estudos Pedagógicos, como uma Campanha Extraordinária de Educação, a ser lançada por métodos semelhantes aos da Campanha de Educação de Adultos, solução que teria a vantagem de ser iniciada imediatamente e que não prejudicaria a continuação dos estudos para a organização definitiva do Serviço de Aperfeiçoamento de Pessoal de Nível Superior. (Teixeira, 1951).

Os pontos aventados no documento de 1951 são reafirmados numa carta de Teixeira, do ano de 1952, ao Ministério da Educação. A missiva abordou a questão das providências imediatas e as qualificou como parte constituinte do "Plano Emergencial da Capes", visto que

[...] além dessas missões de professores estrangeiros, daríamos início simultaneamente à remessa para centros de cultura de fora do país os primeiros bolsistas brasileiros [...] estes dois pontos do programa, a ser, no futuro, em face dos dados apurados, desenvolvidos sistematicamente, constituiriam o que chamaríamos de fase preliminar (sublinhado conforme documento) da Campanha de Aperfeiçoamento de Pessoal de Nível Superior. (Teixeira, 1952).

Depois dos documentos estudados, cabe colocar em discussão a autoria da ideia de criação da Capes - que em diferentes estudos aparece exclusivamente atribuída ao intelectual Anísio Teixeira. Mesmo apresentando o citado intelectual como um dos mais ativos nesse processo, vale explicitar que todas as suas proposições estão no bojo dos diálogos com Clemente Mariani (ministro da Educação no período de 1946 a 1950), nos contatos com os colaboradores do próprio Teixeira na Bahia, com destaque para Jayme Abreu, e nas discussões posteriores da equipe formada por Ernesto Simões Filho, ministro da mesma pasta a partir de 1951, que teve a participação de Teixeira, Péricles Madureira de Pinho e Rômulo Almeida (Gouvêa, 2009).

Percebo que uma instituição de tamanha significação como a Capes não pôde prescindir de um projeto coletivo para sua criação e consolidação, pois "várias foram as estratégias de intervenção empregadas pelo Instituto Nacional de Estudos Pedagógicos (Inep), como órgão responsável pela execução orçamentária da Capes durante o período dos anos 1950-1960". 
Entre tais estratégias, destaco a criação do Centro Brasileiro de Pesquisas Educacionais e os seus Centros Regionais de Pesquisas Educacionais em 1955; ao se instituir uma "rede, o Inep passou a ocupar um papel de vital importância no âmbito das políticas do Ministério da Educação" (Leite Filho, Santos, Gouvêa, 2008).

Os documentos analisados nesta parte do artigo credenciam a inclusão de Teixeira como um dos idealizadores e criadores dessa instituição, pois apontaram de forma explícita a comunhão existente entre o pensamento do intelectual e o processo de gestação, organização e consolidação da Capes, num movimento de pesquisa que buscou captar essa gênese sem considerar leis, decretos ou outros instrumentos legais como os únicos capazes de precisar e balizar os estudos que têm nas instituições a sua centralidade.

A postura anunciada no parágrafo anterior não elimina a importância desses instrumentos, mas entende que eles - isoladamente - não expressam a dinâmica de funcionamento e a estrutura interna de diferentes instituições e sua relação com o contexto histórico que sopra aos ouvidos as brisas e os vendavais de cada época.

\section{O contexto de criação da Capes: os anos 1950}

O período abarcado por este estudo se refere aos dez primeiros anos da Capes e se estende de 1951 a 1960, época marcada por um grande surto de desenvolvimento político-econômico-social do País, o que se constitui num pano de fundo de significativa importância para o entendimento e contextualização do momento de criação dessa instituição.

A dinâmica dos anos 1950 pediu o aprofundamento em duas dimensões distintas e complementares desse momento histórico: a primeira refere-se às formas próprias do processo de organização da sociedade articuladas e expressas na consolidação do Estado Brasileiro, numa tentativa de identificar que tipo de Estado concebeu e efetivou a Capes e a partir de que conjuntura de interesses e forças políticas; enquanto que a segunda dimensão objetivou situar as matrizes econômico-produtivas presentes no momento de criação da Capes que influenciaram o seu surgimento.

Palco de dois governos distintos e, ao mesmo tempo, complementares no que tange ao tratamento e significância da burocracia estatal, o governo de Getúlio Vargas (1951-1954) e o de Juscelino Kubitschek (1956-1960) refletiram o tipo de Estado que vinha se consolidando no Brasil, o que remete ao longo processo de transição que caracterizou o desenvolvimento do capitalismo industrial no País. Ao longo desses anos, foram consolidados modelos de crescimento econômico pautados numa industrialização acelerada, centrada no Poder Executivo, que desencadeou o crescimento do setor público e diversificou suas atividades internas, concretizou as exigências de uma sociedade urbano-industrial em expansão e acelerou 
as transformações institucionais, instaurando uma estrutura de poder mais adequada às tendências da nova configuração econômico-social e mais complexa do que a anterior (Gouvêa et al., 2001).

Entre as transformações sociais profundas desencadeadas pelo processo de industrialização, destaca-se a alteração progressiva da estrutura de poder, que acaba por transformar uma administração pública ineficaz, mal preparada e corrupta em uma máquina políticoadministrativa centrada, principalmente, na eficiência. Entretanto, a despeito da necessária transformação, evidencia-se que a nova máquina estatal se deparou com múltiplas dificuldades quando tentou neutralizar o patrimonialismo, o nepotismo e a dominação pessoal, históricos sustentáculos do comportamento social no Brasil. Mesmo com esses problemas, no âmbito da nova máquina estatal que se constituiu, estabeleceram-se ministérios, superintendências, autarquias, institutos, empresas públicas, sociedades de economia mista, serviços de informações e processamento de dados. O novo modelo de Estado passou a dispor de "organizações, de técnicas e de pessoal (administrativo, burocrático, técnico, político etc) indispensáveis à execução das suas atividades", configurando-se "como aparelho estatal que aos poucos vai incorporando o pensamento tecnocrático e científico, para melhor desempenhar as suas funções" (Ianni, 1986, p. 19).

Ainda no conjunto das novas características assumidas pelo poder, destaca-se uma efetiva e prolongada hegemonia do Estado por meio do Poder Executivo que, na nova estruturação de forças, adquire autonomia e passa a decidir sobre as bases constitucionais, os recursos financeiros, as condições organizatórias do modelo econômico adotado e até dispor sobre o pessoal especializado para atuação que se fizesse necessária, numa evidente atrofia do Poder Legislativo.

Ao longo de todo o período de sua composição, o novo Estado capitalista brasileiro deteve uma natureza modernizante que se expressou de forma contraditória: a centralização da vida política e econômica e a disciplina submetida aos fatores produtivos nas mãos de uma ação estatal intervencionista conviviam com um caráter conservador presente no sistema político, a ser constantemente intermediado por fortes ideologias de Estado. Tendo assumido papéis de destaque, essas ideologias tinham a função de neutralizar as tensões latentes, constituindo-se em instrumentos de legitimação do amplo projeto da nação.

Nesse contexto contraditório que passou a conviver com os sérios problemas resultantes do rápido crescimento industrial é que se insere a problemática questão educacional do País; medidas racionais e práticas foram demandadas para solucionar a inadequação do sistema educacional frente à nova ordem econômica e social emergente, mas o Estado acabou não encontrando maneiras de encaminhar a necessária reforma educacional que se colocava como urgente.

A questão educacional teve em Teixeira um crítico atento, pois entendia que o desenvolvimento nos diversos campos (econômico, político, 
social e cultural) não adviria apenas da prática de uma intervenção estatal na economia, mas sim de uma intervenção que procedesse às necessárias e prementes reformas no sistema nacional de ensino, numa perspectiva de adequação do processo educacional à nova etapa de desenvolvimento econômico. Teixeira (1956, p. 11) asseverou que todas as medidas racionais tomadas pelo Estado, com efeito contrário ao desejado, consubstanciaram

[...] o espírito formal e burocrático de uma falsa técnica administrativa, concebida como uma ciência autônoma de organização e de meios, não distinguiu serviços de controle e fiscalização dos serviços de condução de atividades próprias autônomas como a educação [...] de modo que estes serviços passaram a ser regulados de forma idêntica aos da arrecadação de impostos ou fiscalização da legislação trabalhista.

Seguindo as trilhas desse raciocínio, é interessante explicitar a ação estatal no período de 1951 a 1960 e imbricá-la com a vida institucional da Capes, numa perspectiva de estabelecer encantos/desencantos, concordâncias/tensões e valores proclamados/valores reais no primeiro decênio da instituição. Valores proclamados (consensuais no campo do discurso) e reais (conflituosos no campo do cotidiano) que irão transparecer principalmente nas mensagens presidenciais do período (Teixeira, 1962).

\section{A ação estatal}

A estrutura/ação da burocracia estatal teve um papel proeminente por favorecer uma abordagem que privilegiou o processo de criação de órgãos - em suas diferentes modalidades e distintos graus de autonomia dentro do aparelho do Estado. A análise dessa ação possibilitou, também, um olhar sobre as origens da própria Capes e um levantamento do papel atribuído à Campanha.

O segundo governo de Getúlio Vargas (1951-1954) teve como desafio a defesa de um programa de industrialização voltado para a criação e para o fomento de um capitalismo de cunho nacionalista, autônomo e sob controle nacional, cabendo ao Estado papel estratégico, fundamental e ativo, apoiado numa função mediadora de caráter interno, entre as classes sociais, e externo ao País, com os centros decisórios do capitalismo mundial.

A orientação nacional-desenvolvimentista determinou a necessidade de implementação de um programa de modernização proposto pelo Estado que tornou evidente a inadequação do aparelho estatal face às tarefas relacionadas com o projeto industrializante. Entre as deficiências apontadas na estrutura administrativa, destacava-se o seu alto grau de irracionalidade, que expressava um total desaparelhamento frente às novas funções econômicas e sociais, as quais passariam à atuação do Estado. 
Para a elaboração e a concretização de uma Política Nacional de Desenvolvimento Econômico, diante das necessidades de aparelhamento do Estado, foram criados, em 1951, diversos órgãos setoriais de atuação nacional: a Comissão Nacional de Política Agrária (CNPA), a Comissão de Desenvolvimento Industrial (CDI), a Comissão de Coordenação e Desenvolvimento de Transportes e a Comissão Nacional de Bem-Estar. Nesse mesmo período, somam-se a essas Comissões outras de atuação específica, além de órgãos e agências, totalizando 22 instituições estatais e incluindo a criação da Capes, da Petrobrás, do então denominado Conselho Nacional de Pesquisas (CNPq) e do Banco Nacional de Desenvolvimento (BNDE), entre outras.

Por se tratarem de órgãos setoriais, essas Comissões eram subordinadas à Presidência da República (Poder Executivo) e funcionavam por meio de um presidente e de representantes tanto dos ministérios quanto do setor privado (indústria, comércio e agricultura). Tratava-se de uma nova gestão estatal que apresentou um padrão inédito de atuação do Estado: a empresa pública voltada para estudos e pesquisas e a vinculação setorial do empresariado para projetos nodais de desenvolvimento, evidenciando um modo distinto de inserção dos interesses privados nas estruturas do Estado.

Dando prosseguimento ao reaparelhamento estatal, Vargas, em 1952, anunciou oficialmente uma reforma administrativa radical, que em muito expressou o que já vinha sendo encaminhado. Tratava-se de uma reforma centrada em três pontos: gestão de um sistema duplo de coordenação, transformação do sistema de distribuição e redistribuição dos fundos públicos e um conjunto de medidas envolvendo o importante desmembramento de órgãos e ministérios.

O sistema duplo de coordenação conjugou um sistema direto, comissões interministeriais, e outro indireto, coordenação de todos os projetos e atividades por meio de um Conselho de Planejamento e Coordenação, que foi constituído junto à Presidência da República. A função desse sistema era descentralizar a administração, amparando-a com um mecanismo de direção que garantiria o controle, a unidade e a harmonia da ação estatal. Tendo sido em parte adotado por Vargas, esse sistema evidenciou pontos em comum com a estratégia política de administração paralela amplamente admitida, posteriormente, por Juscelino Kubistchek.

Dois outros aspectos representaram um papel fundamental na ação estatal implementada por Vargas: a ideologia e a prática do planejamento, incorporadas pelo poder público como componentes cada vez mais necessários ao Estado num movimento de progressiva racionalização da política econômica governamental, trazendo como consequência a valorização do "técnico" e a formação de uma "tecnocracia". Nesse complexo circuito, a Assessoria Econômica da Presidência, órgão da administração direta, tinha por objetivos "[...] conceber projetos, levá-los ao Presidente e uma vez aprovados por este, eram eles apresentados aos ministros das pastas respectivas, que lhes assumiam a paternidade e os tocavam em frente" (Córdova, 1998, p. 30). 


\section{Entre valores proclamados e valores reais: a Capes nas mensagens presidenciais}

A Capes mereceu um espaço privilegiado na Mensagem Presidencial de 1952, a qual observou que o órgão foi criado "com a finalidade de suprir as deficiências graves do nosso equipamento técnico e científico". Segue a mensagem estabelecendo a ligação entre o processo de industrialização e a educação, ao asseverar que "o desenvolvimento do País, a feição industrial moderna que vem rapidamente adquirindo, e os problemas de organização que daí decorrem, estão a exigir um rendimento correspondente do pessoal de nível superior". O texto presidencial acrescentou a urgência de "um levantamento das necessidades do País, em matéria de pessoal especializado [...]". Na conclusão da mensagem, foi colocada em evidência que "[...] a política educacional do governo procura assim prestigiar o trabalho universitário e o da alta especialização" (Educação..., 1987, p. 210-211).

O governo Vargas obteve resultados incompletos se comparados com suas ambições originais, principalmente no que se refere ao aparelho de Estado e às políticas gerais pretendidas. Mas, em se tratando dos resultados alcançados pela Capes, seria incorreto fazer tal afirmação haja vista que essa instituição teve seu papel e seus objetivos gradualmente construídos ao longo desses dez anos. A Capes se constituiu numa instituição que deteve um elevado grau de atuação e de influência em importantes desdobramentos relacionados ao fomento da pós-graduação no Brasil. A queda do governo Vargas, em 1954, fruto de um complexo quadro político e econômico repleto de contradições, ocasionou a assunção de Café Filho ao poder. O governo Café Filho, apesar de sua interinidade, destacou na mensagem presidencial de 1955 a contribuição da Capes nas atividades empreendidas pela Comissão no ano anterior e "na realização de cursos de aperfeiçoamento pós-graduado ou de formação especializada" (Educação..., 1987, p. 246).

Após as breves gestões de Carlos Luz e Nereu Ramos, as eleições presidenciais apontaram a vitória de Juscelino Kubistchek. No âmbito das políticas econômicas adotadas, a grande diferença do governo Kubistchek em relação ao segundo governo Vargas foi a transição (casual ou deliberada) de uma política destinada a criar um sistema capitalista nacional "para uma política orientada para o desenvolvimento econômico dependente ou associado" (Ianni, 1986, p. 159). Mais uma vez, ao longo de todo esse processo que marcou a segunda metade dos anos 1950, o Estado teve uma atuação direta em diferentes campos.

Paralelamente, em se tratando dos aspectos endógenos, o País e a sociedade brasileira começavam a assimilar positivamente uma prática governamental pautada numa política econômica planificada, encaminhada anteriormente pelo governo Vargas. A acumulação das experiências anteriores e a sedimentação do debate técnico e político envolvendo temáticas como desenvolvimento, industrialização, economia nacional, planejamento, emancipação econômica, entre outras, haviam preparado 
os grupos políticos e econômicos dominantes para levar adiante a política econômica governamental.

Nesse contexto, a iniciativa estatal concretizou o Plano de Metas que no entender de Benevides (1976, p. 210) "consistia no planejamento de trinta e uma metas distribuídas em seis grandes grupos [...]: energia, transportes, alimentação, indústrias de base, educação (meta 30) e construção de Brasília, a meta síntese."

Articulada ao Plano de Metas, a administração de Kubistchek, além de assimilar os instrumentos e aparelhos de política e regulação econômica herdados do segundo governo Vargas, acabou criando novas formas de articulação política, tendo em vista elevar a coordenação e o controle dos investimentos públicos (Conselho de Desenvolvimento e o próprio Plano de Metas) e dos investimentos privados (Grupos Executivos). Dentro dessa nova dinâmica, três aspectos expressam a essência da administração Kubistchek.

O primeiro aspecto referiu-se ao sucesso da articulação estabelecida entre os nexos de interesse, expressa num tripé constituído pelo Estado, pelo capital estrangeiro e pelo empresariado nacional, voltados para a criação de uma estrutura industrial mais avançada e integrada à nova divisão internacional do trabalho. Encaminhada pelo núcleo político do governo, essa estratégia, que teve no "desenvolvimentismo" sua expressão ideológica e política, atuou de forma a minimizar as possíveis resistências por meio da negociação de interesses.

O segundo aspecto - na compreensão de Draibe (1985, p. 245) se expressou na concepção e concretização de uma estrutura de poder informal, paralela, eficiente e vinculada diretamente à Presidência da República,

[...] cujo caráter não institucionalizado e provisório permitiu circundar as velhas resistências ideológicas à criação de uma instância superior de planejamento, de coordenação do gasto e do investimento público e, ademais, superar os entraves impostos por segmentos burocráticos tradicionais.

A Capes estava incluída nessa modalidade administrativa que expressou um aperfeiçoamento do "sistema duplo de coordenação" introduzido no segundo governo Vargas.

A "administração paralela" representou a resposta do governo Kubistchek à necessidade de uma eficácia gerencial na emperrada burocracia estatal e propiciou o surgimento de um olhar privilegiado para os órgãos que já eram considerados eficientes. Benevides (1976, p. 224) assevera que

[...] a administração paralela era, portanto, um esquema racional, dentro da lógica do sistema - evitando o imobilismo do sistema sem ter que contestá-lo radicalmente - uma vez que os novos órgãos funcionavam como centros de assessoria e execução, enquanto que os antigos continuavam a corresponder aos interesses da política de clientela ainda vigente $[\ldots]$. 
Constituindo-se uma expressão dessa "administração paralela", o próprio Plano de Metas jamais teria se concretizado caso tivesse que passar pelos tradicionais processos de tramitação legislativa, caracterizados por intermináveis negociações.

Finalmente, o terceiro aspecto sinalizou uma opção de política estatal centrada em soluções de conveniência, sem restrições quanto a encaminhamentos marginais; o objetivo maior da ação estatal era conseguir encaminhar o gradual avanço do grau de coordenação e o esforço de investimento público sem que se necessitasse recorrer a uma reforma administrativa, fiscal e financeira de profundidade no País, possíveis expressões dos futuros impasses que possibilitam a compreensão da espiral inflacionária que avançou de maneira célere a partir de 1961 (Melo, Bastos, Araújo, 2006).

Entre as possíveis constatações sobre o tipo de ação estatal adotada por Kubistchek frente às políticas sociais, tais como saúde e educação, nota-se que estas permanecem sendo gestadas e implementadas num processo semelhante ao do governo anterior. Nesse contexto, a Capes surgiu como uma dupla exceção; primeiro, por se adequar sem grandes transformações à nova ação estatal, dentro da mesma linha de sua criação - uma existência não institucionalizada que a situa no âmbito estratégico da administração paralela; e, segundo, por ter sua continuidade garantida a despeito de se constituir num órgão de natureza educacional, o que em parte pode ser explicado por meio do seu papel no encaminhamento de um necessário aperfeiçoamento e capacitação de funcionários oriundos tanto da burocracia estatal quanto da privada, a ser confirmado pela sua denominação de Campanha de Aperfeiçoamento de Pessoal de Nível Superior.

Nas mensagens presidenciais do governo Kubistchek, a Capes apareceu pela primeira vez na de 1957. Nesta, foram relacionadas as atividades desenvolvidas no ano anterior, sinalizando os cinco anos de existência dessa instituição e situando-a no rol das atitudes tomadas pelo governo para "[...] suprir a deficiência de nossas escolas superiores, em face das exigências do crescimento social e econômico do País [...]". A mensagem repetiu formulações de outros governos no que concerne à relação economia/educação, mas merece destaque pelo trecho que asseverava que a Capes (naquele momento) estava "significando, praticamente o primeiro passo no sentido de uma necessária reforma" (Educação..., 1987, p. 275). As mensagens presidenciais de 1958, 1959 e 1960 apenas destacaram os objetivos da Capes e a notícia do prosseguimento de suas atividades.

O breve histórico desenvolvido mostrou que, no período de 1945 até o início da década de 1960, ocorreu a continuidade do modelo de substituição de importações numa perspectiva de aceleração e complexificação. Tal perspectiva foi sustentada pelo modelo de Estado nacional-desenvolvimentista e apoiada pela união da burguesia nacional e do operariado na luta pela implantação e controle do processo de industrialização, num período que assistiu ao surgimento de um outro ator na trama econômica: o capital estrangeiro. 
O governo de Juscelino Kubitschek (1956-1961), num reflexo das consequências do fortalecimento do capital estrangeiro, fomentou no plano político o nacionalismo e, no plano econômico, desnacionalizou o processo de industrialização. A política governamental, mediante posições tão antagônicas, acelerou a entrada das grandes empresas internacionais no País, visto que as indústrias de consumo durável, que faltavam para completar o processo de substituição de importações, requeriam um alto investimento para a sua implantação. Dessa forma, o capital estrangeiro passou a dominar o panorama econômico brasileiro.

Findo o período desse modelo de substituição, emergiram as contradições que permearam os governos de Jânio Quadros e de João Goulart, antes contornadas pelo denominador comum da meta da industrialização, mas que nesse momento se mostraram irreconciliáveis, pois, no entender de Saviani (1991, p. 143),

[...] enquanto para a burguesia e para as classes médias a industrialização era um fim em si mesma, para o operariado e as forças de esquerda ela era apenas uma etapa. Por isso, atingida a meta, enquanto a burguesia busca consolidar seu poder, as forças de esquerda levantam nova bandeira: tratase da nacionalização das empresas estrangeiras, controle de remessas de lucros, de dividendos e as reformas de base (reformas tributária, financeira, agrária, educacional etc.). Tais objetivos eram uma decorrência da ideologia política do nacionalismo desenvolvimentista que, entretanto, entram em conflito com o modelo econômico vigente. Daí a alternativa: ajustar a ideologia política ao modelo econômico ou vice-versa. A revolução de 1964 resolveu o conflito em termos da primeira opção.

A citação, apesar de longa, corporifica a complexidade do momento histórico vivido e permite asseverar que a opção de ajustamento da ideologia política ao modelo econômico - não obstante graves desdobramentos em todos os campos - trouxe sérias consequências à educação e atingiu a própria Capes, pois a ruptura política impôs o fim da gestão de Anísio Teixeira frente à referida instituição.

Para Trigueiro (1983, p. 51), ocorreu "o silenciamento do discurso da educação como a operação da substituição da ratio política pela ratio técnica e a oposição da ideia de eficiência à de participação."

\section{Considerações finais}

A Capes devido a sua categoria de "campanha extraordinária", ou seja, fora da morosidade da burocracia estatal, recebeu um tratamento privilegiado no processo de elaboração e implementação de políticas públicas relativas à sua área de atuação, possibilitando que a autonomia e a credibilidade conquistadas por essa instituição (que operou dentro da estrutura administrativa e financeira do Inep) a credenciassem - em alguns momentos - como o principal órgão de consultas para a elaboração de políticas públicas para a educação do País, superando inclusive o próprio Ministério da Educação. 
Entretanto, tal centralidade não ocorreu sem sobressaltos, pois a leitura dos documentos assinalados na introdução deste trabalho também evidenciou que o nascimento da instituição ocorreu num complexo contexto histórico, que representou um desafio cotidiano à sua sobrevivência num modelo de organização estatal repleto de contradições.

O percurso trilhado por este artigo pretendeu apenas colocar em evidência essas contradições, via análise da ação estatal, numa digressão histórica aos anos 1950 e 1960, como tentativa de estabelecer outros possíveis olhares sobre a Capes, para além de uma simples busca de quem criou, de quem foi exclusivamente a figura principal, de um sujeito único com força descomunal para tocar um projeto de tamanhas proporções. O percurso possibilitou um olhar em rede, no coletivo, no projeto construído a várias mãos e eivado também de discordâncias e oposições, mas, mesmo assim, um projeto coletivo.

O pensamento/ação da Capes sobre o papel da universidade no Brasil buscando empreender as reformas necessárias para a consubstanciação de um locus de criação da Cultura e Ciência nacionais e sinalizando a urgência da criação de um sistema de pós-graduação - significa um marco e um legado para os dias de hoje. Um compromisso que no percurso se revelou um aspecto que paulatinamente imprimiu ritmo à dinâmica de funcionamento da Capes até o momento em que tal perspectiva assumiu uma centralidade dentro do fazer institucional, muitas vezes contrariando ou se antecipando às orientações emanadas e às prioridades estabelecidas pelos documentos legais oriundos das altas esferas de poder no âmbito federal.

A Capes contribuiu para a construção e solidificação da rede que apostou no aperfeiçoamento dos quadros de nível superior do País e para a consolidação e institucionalização da pós-graduação no Brasil, que não pode ser confundida com regulamentação de caráter legal, pois negar tal diferenciação seria, por certo, negar a contribuição de muitos para o que hoje denominamos "sistema nacional de pós-graduação".

Ciente das possíveis lacunas, haja vista o imenso material estudado e as limitações inerentes a qualquer artigo, entendo que numa visão prospectiva elas abrem possibilidades para a realização de estudos posteriores que possam cooperar para o pensamento/ação/construção de políticas públicas educacionais para o tempo presente.

Assim, ao concluir um trabalho que se propôs a um percurso de acompanhamento do primeiro decênio da Capes num tempo passado, sinto-me impelido a visitar o tempo presente, mais precisamente a página na internet da quase sexagenária Capes que traz a missão da instituição: "A Capes tem sido decisiva para os êxitos alcançados pelo sistema nacional de pós-graduação, tanto no que diz respeito à consolidação do quadro atual como na construção das mudanças que o avanço do conhecimento e as demandas da sociedade exigem". Um trecho que por trás de cada palavra, pela expressão de cada linha e pela lembrança de diversos momentos abordados por este artigo soa como uma operação histórica que liga antigos becos a modernas avenidas, velhas estações de trens a novos aeroportos, enfim, um estreitamento entre o passado e o presente. 


\section{Referências bibliográficas}

BENEVIDES, Maria Victoria de Mesquita. O governo Kubitschek: desenvolvimento econômico e estabilidade política. Rio de Janeiro: Paz e Terra, 1976.

BRASIL. Decreto no 29.741, de 11 de julho de 1951. Institui uma Comissão para promover a Campanha Nacional de Aperfeiçoamento de Pessoal de Nível Superior. Lex: Coletânea de Legislação, Edição Federal, p. 324, 1951.

BRASIL. Coordenação de Aperfeiçoamento de Pessoal de Nível Superior (Capes). Disponível em: <http://www.capes.gov.br>. Acesso em: 12 abr. 2010.

CERTEAU, Michel de. A invenção do cotidiano. Petrópolis: Vozes, 1994.

CÓRDOVA, Rogério de Andrade. Capes: origem, realizações, significações. Brasília: Capes, 1998. v. 1.

DRAIBE, Sônia. Rumos e metamorfoses: um estudo sobre a constituição do Estado e as alternativas da industrialização no Brasil, 1930-1960. Rio de Janeiro: Paz e Terra, 1985.

EDUCAÇÃO nas mensagens presidenciais (A). Brasília: Inep, 1987.

ELIAS, Norbert. A sociedade dos indivíduos. Rio de Janeiro: Jorge Zahar, 1994.

GOUVÊA, Fernando. Anísio Teixeira e os treze ministros: a "estratégia doce" de um "apolítico" (1951-1964). In: REUNIÃO ANUAL DA ANPED, 32., 2009, Caxambu. Anais da $32^{a}$ reunião...: Sociedade, cultura e educação: novas regulações? Caxambu, 2009. 1 CD-ROM.

GOUVÊA, Fernando; MENDONÇA, Ana Waleska P. Campos. A contribuição de Anísio Teixeira para a institucionalização da pós-graduação no Brasil: um percurso com os boletins da Capes. Revista Perspectiva, Florianópolis, v. 24, n. 1, p. 111-132, 2006.

GOUVÊA, Fernando et al. A formação dos mestres: a contribuição de Anísio Teixeira para a institucionalização da pós-graduação no Brasil. In: PÔRTO JÚNIOR, Gilson (Org.). Anísio Teixeira e o ensino superior. Brasília: Bárbara Bela, 2001.

IANNI, Octávio. Estado e planejamento econômico no Brasil. Rio de Janeiro: Civilização Brasileira, 1986.

LEITE FILHO; Aristeo; SANTOS, Pablo Bispo dos; GOUVÊA, Fernando. Quando os documentos falam... ouve-se até o silêncio: entre relatórios, decretos e manuscritos, a gestão de Anísio Teixeira no Inep/CBPE (1952-1964). In: MENDONÇA, Ana Waleska P. C.; XAVIER, L. N. Por uma política de formação do magistério nacional: o Inep/MEC dos anos 1950/1960. Brasília: Inep, 2008. 
MELO, Hildete Pereira de; BASTOS, Carlos Pinkusfeld; ARAÚJO, Victor Leonardo de. A política macroeconômica e o reformismo social: impasses de um governo sitiado. In: FERREIRA, Marieta de Moraes (Coord.). João Goulart: entre a memória e a história. Rio de Janeiro: FGV, 2006.

SAVIANI, Dermeval. Educação: do senso comum à consciência filosófica. São Paulo: Cortez, 1991.

TEIXEIRA, Anísio. Sugestões para um plano de auxílio ao ensino superior do país, 1950. Localização: Fundação Getúlio Vargas (FGV). Centro de Pesquisa e Documentação de História Contemporânea do Brasil (Cpdoc). Arquivo Anísio Teixeira. AT pi 50.01.00.

. Fase preliminar da Capes - atitudes emergenciais [relatório]. 1951. Localização: Fundação Getúlio Vargas. Centro de Pesquisa e Documentação de História Contemporânea do Brasil (Cpdoc). Arquivo Anísio Teixeira. AT pi 51.52.00.

. [Carta ao Ministério da Educação]. 1952. Localização: Fundação Getúlio Vargas. Centro de Pesquisa e Documentação de História Contemporânea do Brasil (Cpdoc). Arquivo Anísio Teixeira. AT pi 52.64.00.

A administração pública brasileira e a educação. Revista Brasileira de Estudos Pedagógicos, v. 25, n. 63, p. 3-23, 1956.

. Valores proclamados e valores reais nas instituições escolares brasileiras. Revista Brasileira de Estudos Pedagógicos, v. 37, n. 86, p. 59-79, 1962.

TRIGUEIRO, Dumerval. Existe uma filosofia da educação brasileira? In: . (Org.). Filosofia da educação brasileira. Rio de Janeiro: Civilização Brasileira, 1983. p. 19-47.

Fernando Gouvêa, doutor em Educação pela Pontifícia Universidade Católica do Rio de Janeiro (PUC-RJ), é professor do Departamento de Teoria e Planejamento de Ensino, área de História da Educação, da Universidade Federal Rural do Rio de Janeiro (UFRRJ).

gouveafcf@yahoo.com.br

Recebido em 19 de abril de 2010.

Aprovado em 16 de setembro de 2010. 